\title{
Cerebral cavernous malformations and epilepsy
}

\author{
Issam Awad, M.D., and Pascal Jabbour, M.D. \\ Department of Neurological Surgery, Northwestern University Feinberg School of Medicine, \\ and Evanston Northwestern Healthcare, Evanston, Illinois; and Department of Neurosurgery, \\ Thomas Jefferson University, Philadelphia, Pennsylvania
}

\begin{abstract}
$\checkmark$ Seizures and epilepsy are frequent clinical manifestations of cerebral cavernous malformations (CCMs) and represent the most common symptomatic presentation of supratentorial lesions. Clinicians often diagnose CCMs in patients after a first seizure, or in some cases after obtaining neuroimaging studies in patients suffering from chronic epilepsy previously thought to be idiopathic. In some cases, the lesion is clinically significant solely because of its epileptogenicity, but in others there may be concern about potential hemorrhage or focal neurological deficits from a similar lesion.

The authors present current pathophysiological concepts related to epilepsy associated with CCMs. They discuss the spectrum of seizure disorders associated with these lesions and review the natural history, prognosis, and options for therapeutic intervention.
\end{abstract}

\section{KEY WORDS • cerebral cavernous malformation • epilepsy • lesionectomy • seizure surgery}

$\mathrm{C}$ EREBRAL vascular malformations are known to affect 2 to $4 \%$ of the population, predisposing those affected to a lifetime risk of hemorrhagic stroke and epilepsy. These lesions constitute a heterogeneous group, with different lesion types characterized by distinct angioarchitecture as well as distinct biological mechanisms of genesis and progression. The risk of epilepsy and its mechanisms also vary among the different lesion types; and in making treatment decisions, clinicians must often consider not only the epileptogenicity of a specific lesion, but also the prospective risk and potential sequelae of hemorrhage.

\section{Cerebral Cavernous Malformations}

Cerebral cavernous malformations are clusters of dilated sinusoids filled with blood and lined with endothelium without intervening parenchyma (Fig. 1). They appear to grow by a process of vascular cavern proliferation in the setting of repetitive lesional hemorrhages. The CCMs exhibit brittle vascular morphology devoid of mature vessel wall elements. ${ }^{55,57}$ They do not exhibit the high-flow features of AVMs and are less commonly associated with apoplectic hemorrhage. ${ }^{4,8,18,54}$

\footnotetext{
Abbreviations used in this paper: $\mathrm{AVM}=$ arteriovenous malformation; $\mathrm{CCM}=$ cerebral cavernous malformation; $\mathrm{MR}=$ magnetic resonance.
}

Because of their small size and often isodense appearance related to subacute hemorrhage or microcalcifications, CCMs are commonly missed or misdiagnosed on computed tomography scans of the brain. Moreover, these lesions are angiographically occult. They are, however, easily detected on MR images, where they are characterized by a specific appearance of mixed signal within the lesion itself on $T_{1}$ - and $T_{2}$-weighted sequences, surrounded by a ring of $\mathrm{T}_{2}$ hypointensity from hemosiderin leakage. Smaller CCM lesions may only be revealed by gradient-echo MR images, in which they can be identified because of the lesions' telltale hemorrhagic signal.

In 40 to $60 \%$ percent of cases of CCM, the lesions are solitary. The remaining cases involve multiple lesions and familial inheritance in an autosomal dominant pattern. Three distinct gene foci on chromosomes $7 \mathrm{q}, 7 \mathrm{p}$, and $3 \mathrm{q}$ have each been linked to familial CCM. ${ }^{31}$ The identified proteins encoded by CCM genes appear to interact with the endothelial cytoskeleton during angiogenesis, and are expressed in neural tissue, hence potentially explaining the occurrence of these lesions in the central nervous system. ${ }^{23,31} \mathrm{~A}$ hallmark of familial CCM is the presence of multiple lesions, some of which may only be revealed by gradient-echo MR imaging (Fig. 2). Solitary sporadic (nonfamilial) $\mathrm{CCMs}$ are frequently associated with venous anomalies (as discussed in the following section), and these can easily be recognized on contrast-enhanced $\mathrm{T}_{1}$-weighted MR sequences. 

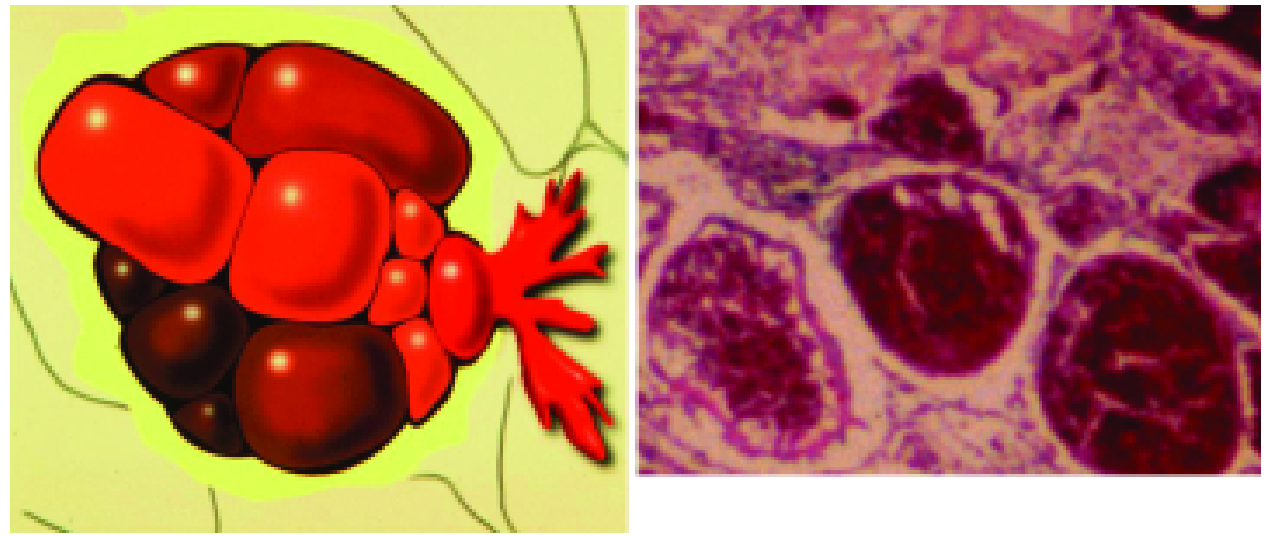

FIG. 1. Left: Drawing depicting the mulberry-like CCM. Right: Photomicrograph showing the blood-filled caverns forming the $\mathrm{CCM}$. $\mathrm{H} \& \mathrm{E}$, original magnification $\times 10$.

\section{Capillary Malformations and CCMs}

Capillary vascular malformations, also known as capillary telangiectases are vascular malformations that consist of a collection of dilated capillaries with normal intervening brain parenchyma. ${ }^{16,58}$ Most commonly located in the pons, they are typically an incidental finding at autopsy, although in some cases, symptomatic capillary malformations have been revealed on MR images as vague patches of punctuate contrast enhancement (Fig. 3). ${ }^{28,37,73}$ Capillary malformations may also be found in association with more clinically overt lesions, such as CCMs or venous malformations. Microscopically, the vessel walls of capillary malformations appear similar to those of normal capillaries, lined with a single layer of vascular endothelium. While both capillary telangiectases and CCMs represent dilated capillaries, the presence of hemorrhage (identifi-

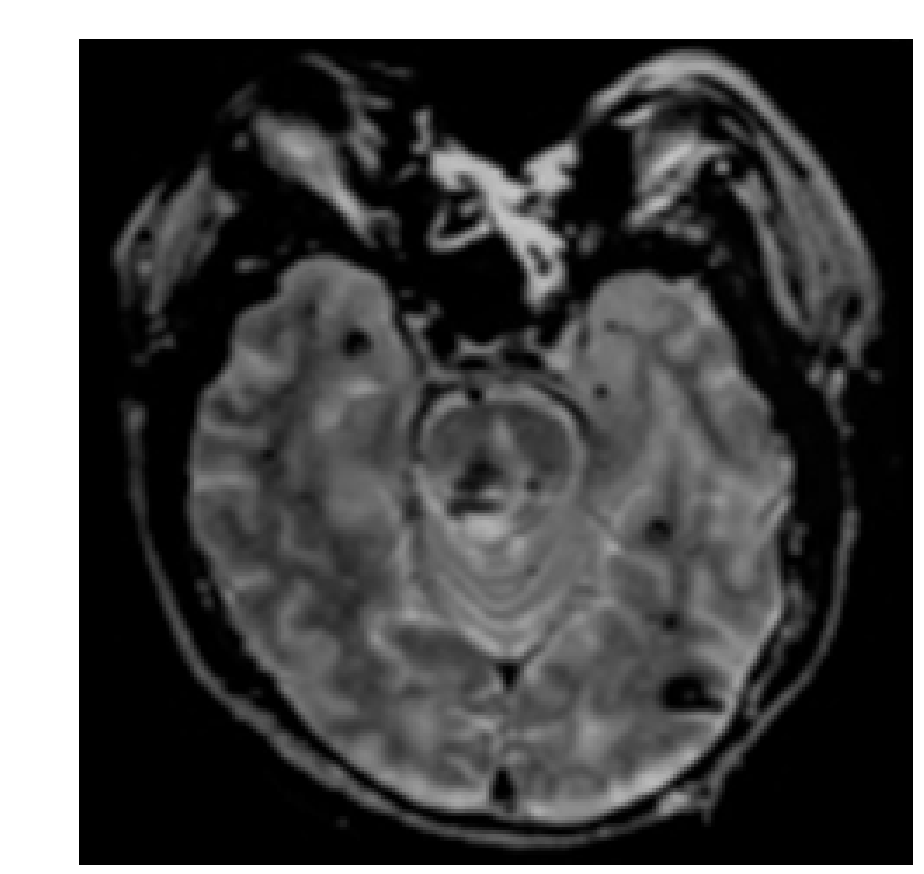

FIG. 2. Axial gradient-echo MR image showing the hemosiderin of multiple CCMs. able on MR imaging or histopathological examination) is a cardinal difference that clearly distinguishes CCMs from capillary malformations.

\section{Cerebral Venous Malformations and CCMs}

The most common form of cerebral vascular malformation is the cerebral venous malformation, also known as venous angioma or developmental venous anomaly. These lesions rarely bleed, except when associated with a CCM (Fig. 4)., ${ }^{1,5}$ They are composed of abnormally enlarged venous channels separated by normal neural parenchyma. ${ }^{32,36}$ The vessels are arranged in a radial pattern extending from a dilated central venous trunk, which itself drains into either a deep or superficial venous sinus..$^{32,43}$

\section{Mixed Vascular Malformations}

Despite the apparently distinct clinical, imaging, and pathological profiles of the various cerebral vascular malformations, some CCM lesions exhibit mixed or transitional features, implying related pathobiological mechanisms. ${ }^{2,15,73,80,81}$ Portions of CCMs may, like AVMs, exhibit partial or complete mature vessel wall elements (Fig. 5), and many CCMs appear to arise in close proximity to venous malformations. It is not known if mixed vascular malformations with a CCM component occur in the setting of genetic predisposition to CCM. Both CCMs and AVMs may be associated with skin lesions in rare cases, although the skin lesions that occur in association with CCMs have not been carefully characterized.

\section{Mechanisms of Epilepsy}

Both diagnosis and treatment of localization-related epilepsy have been greatly improved by modern neuroimaging methods. As a result of advances in neuroimaging, many types of seizures previously classified as cryptogenic have been reclassified as lesional epilepsies that may be amenable to surgical treatment, with resection offering the potential for cure or significant reduction in seizure frequency. Lesional epilepsy is thought to be a direct consequence of a focal brain lesion of neoplastic, vascular, dysgenetic, traumatic, or ischemic origin. 


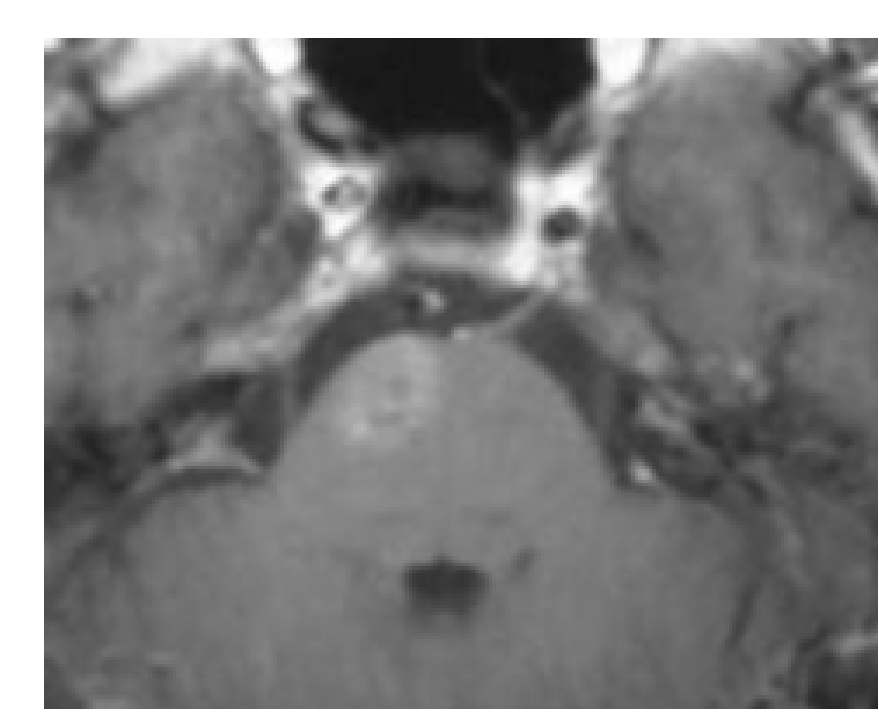

Fig. 3. Axial $\mathrm{T}_{1}$-weighted, Gd-enhanced MR image showing pontine capillary telangiectases.

Localization-related epilepsy is also likely to be affected by individual predisposition, as lesions of identical type, size, and location may cause varying manifestations (including seizure disorders of varying degrees of severity) in different patients. Predisposition may also play a role in seizure intractability, propensity for pharmacological seizure control, and surgical outcome-the likelihood of cure or recurrence of epilepsy after lesion excision.

\section{Epileptogenesis in Adjacent Brain Tissue}

Cerebral cavernous malformations are malformed blood vessels and do not typically include functioning neural tissue. Hence they are not intrinsically epileptogenic, but they can induce seizures through their effect on the surrounding brain tissue. These effects may include ischemia, venous hypertension, gliosis, deposits of blood breakdown products, and cellular and humoral inflammatory responses. Epilepsy in association with CCMs has been shown to induce different firing patterns in adjacent hippocampal tissue slices than epilepsy associated with neoplasia. ${ }^{77}$

These alterations in adjacent brain tissue may induce epileptic activity that depends on the presence of the vascular malformation and may not support epileptic activity in the absence of that primary lesion. Other changes in adjacent brain tissue may represent permanent (independent) epileptogenic foci. In these cases, selective resection of the lesion revealed on MR studies may not be sufficient to abolish all the seizures. ${ }^{25}$ There is thought to be a spectrum of maturation of independent epileptogenicity, and time course is thought to be important in the establishment of independent seizure foci. Thus lesion-related epilepsy is postulated to be more likely to be permanent or to be independent of the instigating pathology after a longer duration of epileptogenicity.

Overt hemorrhage from CCMs may create encephalomalacia and cortical scars that may be independently epileptogenic. These sequelae are often observed on MR imaging and may be associated with focal neurological deficits. Chronic deposition of blood breakdown products is characteristic of CCMs, and gliotic hemosiderin-stained brain tissue adjacent to the lesions is thought to be a source of epileptogenic activity.

\section{Epileptogenesis in Remote Brain Regions}

Lesions may induce changes in brain tissue located at a significant distance from the primary epileptogenic focus, and this may contribute to an epilepsy syndrome, and even to independent distant foci of epileptogenicity. The limbic structures, and to a lesser extent the neocortex, may "learn" to generate seizures independently and may become secondarily epileptogenic after repeated exposure to the seizures caused by an epileptogenic lesion. Over time, network relationships may be altered in such a way as to lead to secondary epileptogenesis in these remote regions. ${ }^{34}$ This process has been most frequently demonstrated in the mesial temporal structures adjacent to structural lesions, and is much less likely to occur in the human neocortex.

The demonstration of dual epileptogenic activity in association with a single CCM does not necessarily imply that the second focus, the one that is more remote from the lesion, will remain active after lesion excision. In fact, this seems to be uncommon in the setting of seizure disorders associated with single vascular malformations. For this reason, a staged approach is often best in such cases: the lesion and surrounding epileptogenic brain tissue are excised during an initial operation, and more extensive investigations of the remaining epileptogenicity and possible further treatment for it are performed only in those uncommon cases in which seizures persist after lesionectomy. The more frequent the seizures, the more likely it is that a secondary focus will become permanent. This observation has led to the recommendation of early surgical intervention when medical therapy fails to control seizures. ${ }^{39}$

\section{Multiple Lesions}

Dual and multifocal lesions are important for the understanding of the pathogenesis of epilepsy, however such cases require careful surgical planning. When patients are known to harbor multiple structural lesions, more extensive preoperative investigations and tailoring of interventions are required for seizure control. ${ }^{22,46,59}$

Cerebral cavernous malformations are frequently associated with multifocal vascular lesions, any one of which may contribute to epileptogenesis. While larger lesions or those most recently associated with bleeding or other clinical manifestations are more likely to be the source of seizures than smaller lesions or those with less apparent clinical importance, this cannot be taken for granted. Resection of the wrong lesion will not only fail to control seizures, but it may also result in catastrophic functional sequelae when the remaining epileptogenic lesion is located in the contralateral temporal or frontal lobe.

In the setting of cerebral vascular malformations, it is important to use the most sensitive imaging studies to identify or exclude multifocal structural pathological conditions that may be contributing to epileptogenicity. In cases of CCM or venous malformation, gradient-echo MR images must be performed to identify or exclude multiple foci of occult hemorrhage. 


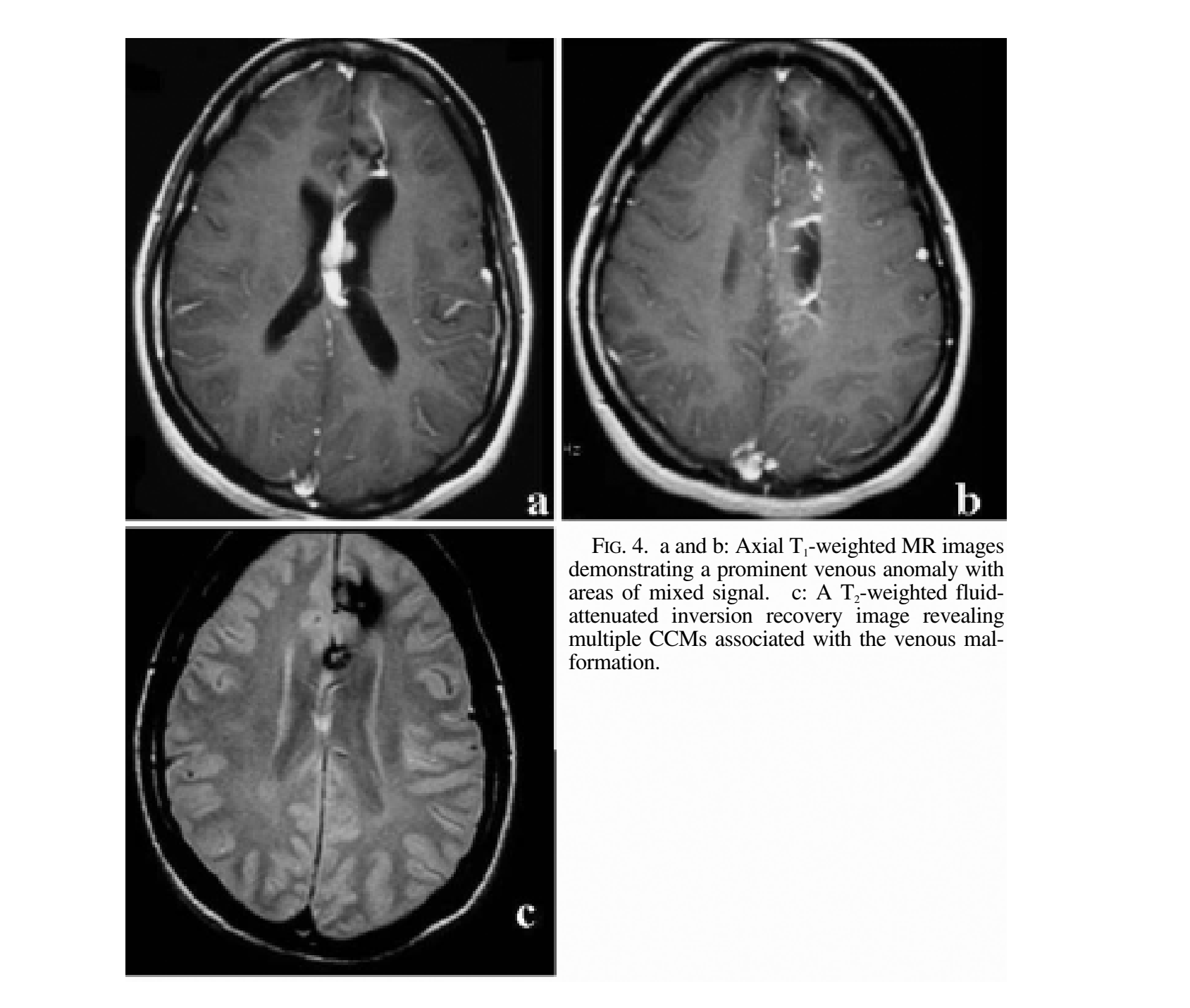

\section{Treatment Options}

\section{Medical Therapies}

The first-line treatment for seizures associated with vascular malformation is always medical. Different anticonvulsant agents are associated with varying degrees of effectiveness for different seizure types; several newer drugs are associated with fewer side effects and may be more safely prescribed for pregnant women. After a patient's first seizure, a decision is typically made about whether to prescribe anticonvulsant medication. This decision is based on the risk of seizure recurrence and on the potential risks associated with chronic antiepileptic therapy. Whenever a structural lesion is identified on imaging studies, a decision must also be made about its probable relationship to the seizure disorder. In the setting of cortical CCM, and certainly when seizure symptoms clearly correspond to the lesion location, this relationship is easy to establish. In other cases, such as those involving infratentorial or subcortical vascular anomalies or seizures precipitated by alcohol, drugs, or trauma, the possibility of an incidental lesion should be considered, especially when seizure symptoms do not suggest appropriate localization. Venous malformations are extremely common in the gen- eral population and often occur together with various neurological symptoms, including seizures, without any causal relationship. Electrophysiological studies may be helpful in this regard, especially when they yield positive results with appropriate lateralization or the identification of an epileptogenic focus; negative results on electroencephalography do not rule out epileptogenicity for a lesion.

When seizures are thought to be caused by CCMs, long-term anticonvulsant therapy is indicated, as the seizures will probably recur and may progress to intractability. A drug should be chosen on the basis of the seizure and the individual patient's tolerance for the potential side effects of different anticonvulsant medications. The selected drug is almost always initially prescribed as monotherapy. Only when seizures recur despite verified compliance and therapeutic doses of this agent is a second agent added.

Patients with CCMs in cortical locations are subject to a prospective lifetime risk of new seizures. This risk is greatest with CCMs situated in temporal, frontal, and perilimbic locations, and may affect occupational clearance (for example, in professional airplane pilots). Clinical history is important in managing such cases, and care should be taken to elicit information about auras or other symp- 


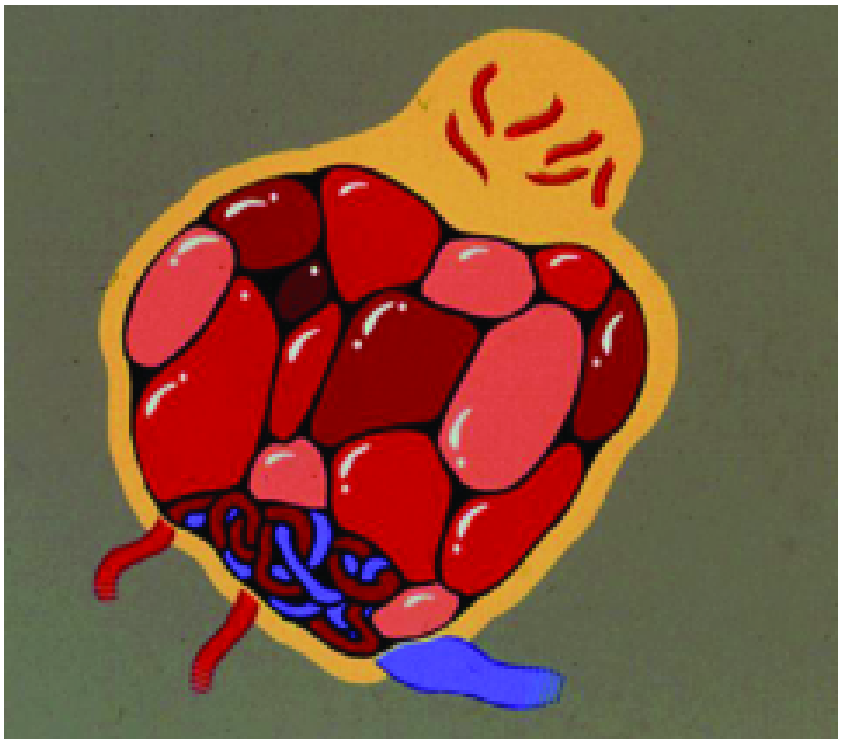

FIG. 5. Artist's rendition showing areas of a CCM with mature vessel wall mimicking an AVM and other areas of associated capillary telangiectasia. The integration of information from imaging and pathological studies is necessary for lesion definition.

toms that may represent seizure activity. Nevertheless, prophylactic treatment is rarely indicated for these patients unless epileptic activity has been established.

\section{Lesion Excision}

Resection of vascular malformations may be undertaken to prevent future hemorrhage and/or for seizure control. Lesionectomy is associated with excellent postoperative seizure control in many patients. ${ }^{4}$ The likelihood of postoperative seizure control following simple lesion excision is greater in patients with less intractable preoperative epilepsy and also in patients with extratemporal lesions. Unlike temporal lobectomy, there are no anatomically standard operations for performing a simple lesionectomy. The procedures are divided into temporal lesionectomies and extratemporal lesionectomies. In patients with temporal lesions and intractable epilepsy, studies in which a simple lesionectomy was performed without resection of mesial structures showed a low seizure control rate ranging from 20 to $45 \% .^{14,33,38}$ In cases of extratemporal lesional epilepsy, lesion resection alone has provided favorable results, with seizure control rates varying from 65 to $95 \% .^{7,14}$

Most patients in whom seizures are fully controlled postoperatively will still require long-term anticonvulsant therapy, although often with fewer agents and at lower dosages than they required preoperatively. When the decision is made to reduce or discontinue anticonvulsant therapy, it is important to taper the dosage cautiously to avoid precipitating new or recurrent seizures. Of patients who harbor a single CCM, undergo lesionectomy for treatment of recent-onset, localization-related seizures, and are seizure free postoperatively, up to half may successfully taper off all anticonvulsant medications. ${ }^{21,35,64,69}$ This promising outcome, and its associated positive impact on qual- ity of life, may play a role in the decision to excise a solitary accessible cortical CCM, even when seizures are not truly intractable to medical therapy.

\section{Lesionectomy and Corticectomy}

Resection of structural lesions may be limited to resection of the lesion alone or may entail resection of the lesion and the epileptogenic cortex. A tailored resection may be performed to avoid the eloquent cortex. Many studies ${ }^{7,12,33,66}$ have compared lesionectomy with the combination of lesionectomy and corticectomy, but the results have been controversial. A metaanalysis evaluating seizure outcome following either lesionectomy or the combination of lesionectomy and corticectomy concluded that at 2-year follow up, the percentage of patients with persistent seizures following lesionectomy ranged from 1.4 to 4 times the percentage of those who had persistent seizures following the combined procedure. Low-grade gliomas, gangliogliomas, and vascular malformations were most successfully treated with lesionectomy and corticectomy. ${ }^{76}$ In contrast, patients with fewer seizures before presentation, shorter preoperative seizure histories, or seizures that responded to antiepileptic medications were more likely to be seizure free following lesionectomy alone. 13,17,49,52, $56,82,83$

Several studies have shown that complete lesion excision is necessary for seizure control in the majority of patients who harbor a CCM that has been shown to be responsible for their seizures. ${ }^{7}$ It also is well documented that lesion excision alone may not always suffice for seizure control, especially in patients with truly intractable epilepsy. Many patients who have had persistent intractable seizures following lesion excision have had lesions in the temporal lobe ${ }^{14}$ Some of these patients became seizure free after additional resection of epileptogenic brain tissue in the same region.

When epileptogenic brain tissue is resected in addition to the lesion during a first operation, it may provide the patient with seizure control and spare him or her a second surgical intervention. But the potential functional impact of resection of additional brain tissue must be considered, especially when contemplating resection of mesial structures in the presence of high or normal material-specific memory function, or resection involving other eloquent areas (such as the dominant temporal neocortex).

Intraoperative electrocorticography is sometimes performed to further delineate the extent of the cortical epileptogenic zone. This technique may provide prognostic information by indicating the areas of residual electric discharges after the resection of the vascular malformation or what was thought to be the seizure focus. ${ }^{10,20,45,47} \mathrm{It}$ is important to remember, however, that residual spikes in adjacent brain areas do not reliably predict residual epileptogenicity, nor does their absence guarantee postoperative seizure control.

\section{Disconnection Surgery}

Multiple subpial transections are mainly used to treat patients with partial epilepsies associated with epileptic foci within eloquent cortical regions. ${ }^{65}$ The technique, which involves interrupting the gray matter columns, can inhibit synchronization and spread of seizure activity with 
less drastic effects on eloquent function. ${ }^{3,40-42}$ Most patients who have undergone multiple subpial transections in eloquent brain tissue have had subtle and transient postoperative deficits that correspond to the transected areas and are most pronounced in the first week after surgery. $19,30,48,60,63$

Corpus callosotomy is another palliative treatment that may be beneficial for patients with multiple or poorly lateralized epileptogenic foci, secondarily generalized tonicclonic seizures, and injurious drop attacks (those that result in falls and injury) due to tonic or atonic seizures. ${ }^{67,68,79}$ Elimination or a more than $80 \%$ reduction in seizures has been reported in $70 \%$ of patients who underwent this treatment. ${ }^{51,67,68}$ Complications specific to this procedure consist of acute disconnection syndromes; these are more common after total callosotomy. ${ }^{50}$

\section{Neuroaugmentative Surgery}

Vagus nerve stimulation is a palliative treatment for intractable seizures. Published data documents seizure reduction rates varying from 35 to $75 \%$ in the setting of various seizure types, with most patients remaining on anticonvulsants postoperatively. Related side effects can include voice alteration, hoarseness, throat or neck pain, headache, cough, dyspnea, vocal cord paralysis, and aspiration. ${ }^{11,44,61,62}$ The procedure is technically relatively simple, but it is very important to talk with patients before surgery about their expectations regarding outcome. To our knowledge, no results have been reported for vagus nerve stimulation applied specifically to the treatment of seizures associated with cerebrovascular malformations.

Deep brain stimulation has been attempted for the modulation of seizure activity, with electrode stimulation targets in the cerebellum; in the anterior, centromedian, and ventralis intermedius thalamic nuclei; and in the caudate nucleus. ${ }^{9,74}$ Stimulation of the hippocampus has recently been used in an attempt to block temporal lobe seizures. ${ }^{75}$ Stimulation of the subthalamic nucleus has been shown to reduce daytime seizures by $80 \%{ }^{9}$

\section{Management Strategies}

\section{First Seizure}

Surgery is rarely considered for seizure control in patients with a first seizure in association with a known or newly diagnosed vascular malformation. Lesion excision may be performed for the purpose of preventing hemorrhage, and in rare cases, especially those involving solitary and accessible CCMs, to provide patients with a chance of being able to discontinue anticonvulsant medications. Medical treatment is typically initiated to try to determine whether a patient's seizures may be classified as well-controlled or uncontrolled.

Cerebral cavernous malformations are known to be more epileptogenic than other cerebrovascular anomalies, as they are more frequently associated with seizures in general and with intractable seizures in particular. The exact mechanisms by which CCMs cause seizures are unknown, although a number of electrophysiological and pathophysiological theories have been proposed. These include changes in neurotransmitter levels $(\gamma$-aminobu- tyric acid and somatostatin), free radical formation, and altered second messenger function. ${ }^{26}$ Morphological changes have also been identified, including alterations in vascular supply, neuronal cell loss, glial proliferation, and subtle subcortical disconnections. ${ }^{35}$ It is commonly believed that the breakdown products caused by repeated microhemorrhages deposit ferric ions, which are known to be highly epileptogenic, into the cortex around the lesion. In animals, the injection of ferric ions into the cortex and subcortical regions creates a potent and reproducible model of recurrent and intractable seizures. ${ }^{78}$ These different pathophysiological mechanisms may present opportunities for developing specific anticonvulsant strategies.

Cerebral cavernous malformations in the rolandic or perirolandic cortex, as well as near limbic areas (temporal lobe and cingulate gyrus lesions), are typically the most epileptogenic. Lesion size may represent an additional factor in epileptogenicity. A final issue that must be considered is the possibility that the CCM identified on imaging may represent an incidental finding and may not play any role in seizure onset. This may be the situation in up to $6 \%$ of cases of patients with cavernous angiomas and epilepsy ${ }^{53}$ In some cases, CCMs may represent structural lesions coexistent with mesial temporal sclerosis.

Although there is only minimal risk of hemorrhage in capillary telangiectasia, there are reports in the literature describing the association of capillary malformation with seizures and hemorrhage. ${ }^{27,29}$ Seizures can occur as a direct result of hemorrhage caused by the capillary malformation, and such a hemorrhage is likely to convert the lesion into a CCM.

Venous angiomas are rarely associated with seizures. Moreover these lesions are usually difficult to relate causally and topographically to an epileptogenic zone. ${ }^{6,70,71}$ These lesions are typically observed as incidental findings during diagnostic evaluations. Venous angiomas are often associated with CCMs, and seizures in this setting are probably due to the CCM rather than the venous angioma. ${ }^{670-72}$ Rarely, brain dysmorphisms (gyral or lobar developmental anomalies) may be associated with regional venous dysmorphisms. In those instances, the venous anomaly is an index for associated dysmorphic brain tissue that may be epileptogenic. Careful electrophysiological studies as well as interictal and ictal functional imaging are indicated in these cases to explore whether the lesion is associated with an epileptogenic zone.

\section{Controlled Seizures}

Regardless of the type of vascular malformation, surgical intervention is not typically warranted in cases of wellcontrolled epilepsy unless there is another indication for it. Often, however, lesion excision is contemplated to prevent hemorrhage without any expectation of improving seizure control.

Resection of a vascular malformation might be undertaken for seizure control in patients who are not compliant with their antiepileptic medication regimen but whose seizures are otherwise amenable to medical control. Similarly, patients who do not want to continue to take antiepileptic medications because of concerns about adverse effects or other issues may also benefit from resection. In these cases, it is very important to take into account the lo- 
cation of the malformation and the feasibility of the procedure, weighing the risks and potential benefits, and to remember that enhanced seizure control or discontinuation of medication cannot be guaranteed.

Patients with well-controlled seizures who harbor a CCM may require treatment of the lesion for reasons other than seizure control-mainly for the purpose of reducing the risk of hemorrhage. Patients with CCMs have a lower risk of apoplectic hemorrhage than those harboring AVMs, but lesions with prior overt hemorrhage or demonstrated growth are often considered for excision to prevent further neurological sequelae.

\section{Prognosis and Outcome of Intractable Seizures}

The presence of a vascular malformation in association with intractable seizures is a challenging situation. Resection is usually performed in an attempt to control the seizures.

Patients who have solitary CCMs associated with uncontrolled epilepsy and symptoms related to lesion location are candidates for surgical excision of the CCM with the goal of improving seizure control. Overall analysis of the published outcome data demonstrates symptom improvement in the majority of such patients. . $^{418,24,54}$ Among patients treated with surgical resection of the offending lesion, 50 to $90 \%$ were seizure free postoperatively with or without anticonvulsant therapy. ${ }^{18,24,54}$ Persistent seizures have been reported in conjunction with incomplete resection. In order to maximize the likelihood of seizure control, excision of the CCM should be accompanied, whenever feasible (that is, in noneloquent brain regions), by resection of the gliotic hemosiderin-stained brain parenchyma surrounding the lesion. . $^{4,618,64}$

There is no evidence that extensive preoperative mapping or additional brain tissue excision at initial surgery will improve seizure outcome beyond what can be obtained with lesionectomy and resection of perilesional gliotic brain tissue in cases of solitary CCMs and intractable epilepsy. In the rare cases, in which patients suffer residual or recurrent seizures after lesionectomy, a second operation may be considered for resection of residual lesion and/or adjacent or remote epileptogenic brain tissue. As in other cases of localization-related epilepsy, such repeated operations require comprehensive preoperative and intraoperative mapping as well as functional studies.

When there is any question whatsoever about the relationship of a CCM to an intractable seizure disorder, patients should not undergo empiric lesion resection in the remote hope that intractable epilepsy might resolve. Instead, detailed preoperative mapping and recording should be performed. This is particularly true in cases involving multiple CCMs, in which a single epileptogenic lesion is not always easy to isolate. In these cases, careful preoperative mapping and other diagnostic studies must be performed before resection of a specific lesion is proposed for seizure control.

\section{Conclusions}

The direct relationship between CCMs and seizures is not always clear. Prolonged preoperative mapping and careful recording are mandatory for clarifying cases in which the lesion may not be the primary epileptogenic source, may simply be incidental or unrelated to the seizure disorder, or in cases involving multifocal lesions. In patients harboring a solitary CCM that is believed to be epileptogenic, optimum seizure control is achieved through complete resection of the lesion, along with surrounding hemosiderin-stained brain tissue, if the lesion is in a noneloquent location. The threshold for considering lesion excision depends on the projected natural history of the lesion as well as its surgical accessibility. In the different scenarios, patients and their family members should be advised of all expectations related to all treatments under consideration.

\section{References}

1. Abdulrauf SI, Kaynar MY, Awad IA: A comparison of the clinical profile of cavernous malformations with and without associated venous malformations. Neurosurgery 44:41-47, 1999

2. Aksoy FG, Gomori JM, Tuchner Z: Association of intracerebral venous angioma and true arteriovenous malformation: a rare, distinct entity. Neuroradiology 42:455-457, 2000

3. Asanuma H: Recent developments in the study of the columnar arrangement of neurons within the motor cortex. Physiol Rev 55:143-156, 1975

4. Awad IA, Barrow DL (eds): Cavernous Malformations. Park Ridge, IL: American Association of Neurological Surgeons, 1993

5. Awad IA, Robinson JR: Comparison of the clinical presentation of symptomatic arteriovenous malformations (angiographically visualized) and occult vascular malformations. Neurosurgery 32:876-878, 1993

6. Awad IA, Robinson JR Jr, Mohanty S, Estes ML: Mixed vascular malformations of the brain: clinical and pathogenetic considerations. Neurosurgery 33:179-188, 1993

7. Awad IA, Rosenfeld J, Ahl J, Hahn JF, Luders H: Intractable epilepsy and structural lesions of the brain: mapping, resection strategies, and seizure outcome. Epilepsia 32:179-186, 1991

8. Beck L Jr, D'Amore PA: Vascular development: cellular and molecular regulation. FASEB J 11:365-373, 1997

9. Benabid AL, Minotti L, Koudsie A, de Saint Martin A, Hirsch E: Antiepileptic effect of high-frequency stimulation of the subthalamic nucleus (corpus luysi) in a case of medically intractable epilepsy caused by focal dysplasia: a 30-month followup: technical case report. Neurosurgery 50:1385-1392, 2002

10. Bengzon AR, Rasmussen T, Gloor P, Dussault J, Stephens M: Prognostic factors in the surgical treatment of temporal lobe epileptics. Neurology 18:717-731, 1968

11. Ben-Menachem E, Hellström K, Verstappen D: Analysis of direct hospital costs before and 18 months after treatment with vagus nerve stimulation therapy in 43 patients. Neurology 59 (Suppl 4):S44-S47, 2002

12. Britton JW, Cascino GD, Sharbrough FW, Kelly PJ: Low-grade glial neoplasms and intractable partial epilepsy: efficacy of surgical treatment. Epilepsia 35:1130-1135, 1994

13. Cappabianca P, Alfieri A, Maiuri F, Mariniello G, Cirillo S, de Divitiis E: Supratentorial cavernous malformations and epilepsy: seizure outcome after lesionectomy on a series of 35 patients. Clin Neurol Neurosurg 99:179-183, 1997

14. Cascino GD, Kelly PJ, Sharbrough FW, Hulihan JF, Hirschorn KA, Trenerry MR: Long-term follow-up of stereotactic lesionectomy in partial epilepsy: predictive factors and electroencephalographic results. Epilepsia 33:639-644, 1992

15. Chang SD, Steinberg GK, Rosario M, Crowley RS, Hevner RF: Mixed arteriovenous malformation and capillary telangiectasia: a rare subset of mixed vascular malformations. Case report. J Neurosurg 86:699-703, 1997 
16. Chusid JG, Kopeloff LM: Epileptogenic effects of pure metals implanted in motor cortex of monkeys. J Appl Physiol 17: 697-700, 1962

17. Cohen DS, Zubay GP, Goodman RR: Seizure outcome after lesionectomy for cavernous malformations. J Neurosurg 83: 237-242, 1995

18. Del Curling O Jr, Kelly DL Jr, Elster AD, Craven TE: An analysis of the natural history of cavernous angiomas. J Neurosurg 75:702-708, 1991

19. Devinsky O, Perrine K, Vazquez B, Luciano DJ, Dogali M: Multiple subpial transections in the language cortex. Brain 117:255-265, 1994

20. Dodrill CB, Wilkus RJ, Ojemann GA, Ward AA, Wyler AR, van Belle G, et al: Multidisciplinary prediction of seizure relief from cortical resection surgery. Ann Neurol 20:2-12, 1986

21. Dorsch NWC, McMahon JHA: Intracranial cavernous malformations-natural history and management. Crit Rev Neurosurg 8:154-168, 1998

22. Eriksson SH, Nordborg C, Rydenhag B, Malmgren K: Parenchymal lesions in pharmacoresistant temporal lobe epilepsy: dual and multiple pathology. Acta Neurol Scand 112: $151-156,2005$

23. Gault J, Sarin H, Awadallah NA, Shenkar R, Awad IA: Pathobiology of human cerebrovascular malformations: basic mechanisms and clinical relevance. Neurosurgery 55:1-17, 2004

24. Giombini S, Morello G: Cavernous angiomas of the brain. Account of fourteen personal cases and review of the literature. Acta Neurochir (Wien) 40:61-82, 1978

25. Hadar E, Lüders J: General and historical considerations of epilepsy surgery, in Winn HR (ed): Youmans Neurological Surgery, ed 5. Philadelphia: Saunders, 2004, Vol 2, pp 2435-2448 26

26. Haglund MM, Berger MS, Kunkel DD, Franck JE, Ghatan S, Ojemann GA: Changes in gamma-aminobutyric acid and somatostatin in epileptic cortex associated with low-grade gliomas. J Neurosurg 77:209-216, 1992

27. Hisada K, Morioka T, Nishio S, Amano T, Iwaki T, Fukui M: [Temporal lobe epilepsy associated with old intracerebral hemorrhage due to capillary telangiectasis in the temporal lobe: case report.] No To Shinkei 51:729-735, 1999 (Jpn)

28. Hoang TA, Hasso AN: Intracranial vascular malformations. Neuroimaging Clin N Am 4:823-847, 1994

29. Huddle DC, Chaloupka JC, Sehgal V: Clinically aggressive diffuse capillary telangiectasia of the brain stem: a clinical radiologic-pathologic case study. AJNR Am J Neuroradiol 20: 1674-1677, 1999

30. Hufnagel A, Zentner J, Fernandez G, Wolf HK, Schramm J, Elger CE: Multiple subpial transection for control of epileptic seizures: effectiveness and safety. Epilepsia 38:678-688, 1997

31. Jabbour P, Gault J, Awad IA: What genes can teach us about human cerebrovascular malformations. Clin Neurosurg 51: 140-152, 2004

32. Johnson PC WT, Golfinos J, Spetzler RF: Definition and pathologic features, in Awad IA, Barrow DL (eds): Cavernous Malformations. Park Ridge, IL: American Association of Neurological Surgeons, 1993, pp 1-11

33. Jooma R, Yeh HS, Privitera MD, Gartner M: Lesionectomy versus electrophysiologically guided resection for temporal lobe tumors manifesting with complex partial seizures. J Neurosurg 83:231-236, 1995

34. Kerrigan JF, Ng YT, Chung S, Rekate HL: The hypothalamic hamartoma: a model of subcortical epileptogenesis and encephalopathy. Semin Pediatr Neurol 12:119-131, 2005

35. Kraemer DL, Awad IA: Vascular malformations and epilepsy: clinical considerations and basic mechanisms. Epilepsia 35 (Suppl 6):S30-S43, 1994

36. Martin N, Vintners H: Pathology and grading of intracranial malformations, in Barrow DL (ed): Intracranial Vascular
Malformations. Park Ridge, IL: American Association of Neurological Surgeons, 1990 pp 1-30

37. McCormick PW, Spetzler RF, Johnson PC, Drayer BP: Cerebellar hemorrhage associated with capillary telangiectasia and venous angioma: a case report. Surg Neurol 39:451-457, 1993

38. Moore JL, Cascino GD, Trenerry MR, Kelly PJ, Marsh WR: A comparative study of lesionectomy versus corticectomy in patients with temporal lobe lesional epilepsy. J Epilepsy 6: 239-242, 1993

39. Morrell F: Varieties of human secondary epileptogenesis. J Clin Neurophysiol 6:227-275, 1989

40. Morrell F, Whisler WW, Bleck TP: Multiple subpial transection: a new approach to the surgical treatment of focal epilepsy. J Neurosurg 70:231-239, 1989

41. Mountcastle VB: The columnar organization of the neocortex. Brain 120:701-722, 1997

42. Mountcastle VB: Modality and topographic properties of single neurons of cat's somatic sensory cortex. J Neurophysiol 20: 408-434, 1957

43. Mullan S, Mojtahedi S, Johnson DL, Macdonald RL: Cerebral venous malformation- arteriovenous malformation transition forms. J Neurosurg 85:9-13, 1996

44. Murphy JV: Left vagal nerve stimulation in children with medically refractory epilepsy. The Pediatric VNS Study Group. J Pediatr 134:563-566, 1999

45. Ojemann GA: Surgical treatment of epilepsy, in Wilkins RH, Rengachary SS (eds): Neurosurgery, ed 2. New York: McGraw Hill, 1996, pp 4173-4183

46. Okujava M, Ebner A, Schmitt J, Woermann F: Cavernous angioma associated with ipsilateral hippocampal sclerosis. Eur Radiol 12: 1840-1842, 2002

47. Olivier A, Awad IA: Extratemporal resections, in Engel JJ Jr (ed): Surgical Treatment of the Epilepsies. New York: Raven Press, 1993, pp 489-500

48. Pacia SV, Devinsky O, Perrine K, Luciano Dj, Vazquez B, Doyle WK, et al: Multiple subpial transections for intractable partial seizures: seizure outcome. J Epilepsy 10:86-91, 1997

49. Packer RJ, Sutton LN, Patel KM, Duhaime AC, Schiff S, Weinstein SR, et al: Seizure control following tumor surgery for childhood cortical low-grade gliomas. J Neurosurg 80: 998-1003, 1994

50. Pilcher WH, Silbergeld DL, Berger MS, Ojemann GA: Intraoperative electrocorticography during tumor resection: impact on seizure outcome in patients with gangliogliomas. J Neurosurg 78:891-902, 1993

51. Purves SJ, Wada JA, Woodhurst WB, Moyes PD, Strauss E, Kosaka B, et al: Results of anterior corpus callosum section in 24 patients with medically intractable seizures. Neurology 38: 1194-1201, 1988

52. Rassi-Neto A, Ferraz FP, Campos CR, Braga FM: Patients with epileptic seizures and cerebral lesions who underwent lesionectomy restricted to or associated with the adjacent irritative area. Epilepsia 40:856-864, 1999

53. Requena I, Arias M, Lopez-Ibor L, Pereiro I, Barba A, Alonso A, et al: Cavernomas of the central nervous system: clinical and neuroimaging manifestations in 47 patients. J Neurol Neurosurg Psychiatry 54:590-594, 1991

54. Robinson JR, Awad IA, Little JR: Natural history of the cavernous angioma. J Neurosurg 75:709-714, 1991

55. Robinson JR Jr, Awad IA, Masaryk TJ, Estes ML: Pathological heterogeneity of angiographically occult vascular malformations of the brain. Neurosurgery 33:547-555, 1993

56. Rossi GF, Pompucci A, Colicchio G, Scerrati M: Factors of surgical outcome in tumoral epilepsy. Acta Neurochir (Wien) 141:819-824, 1999

57. Rothbart D, Awad IA, Lee J, Kim J, Harbaugh R, Criscuolo GR: Expression of angiogenic factors and structural proteins in central nervous system vascular malformations. Neurosurgery 38:915-925, 1996 
58. Russell DS, Rubenstein LJ: Pathology of Tumors of the Nervous System, ed 5. Baltimore: Williams \& Wilkins, 1989

59. Salanova V, Markand O, Worth R: Temporal lobe epilepsy: analysis of patients with dual pathology. Acta Neurol Scand 109: 126-131, 2004

60. Sawhney IM, Robertson IJ, Polkey CE, Binnie CD, Elwes RD: Multiple subpial transection: a review of 21 cases. J Neurol Neurosurg Psychiatry 58:344-349, 1995

61. Schachter SC: Vagus nerve stimulation therapy summary: five years after FDA approval. Neurology 59 (Suppl 4):S15-S20, 2002

62. Schachter SC, Wheless JW: The evolving place of vagus nerve stimulation therapy. Neurology 59 (Suppl 4):S1-S2, 2002

63. Shimizu H, Suzuki I, Ishijima B, Karasawa S, Sakuma T: Multiple subpial transection (MST) for the control of seizures that originated in unresectable cortical foci. Jpn J Psychiatry Neurol 45:354-356, 1991

64. Siegel AM, Roberts DW, Harbaugh RE, Williamson PD: Pure lesionectomy versus tailored epilepsy surgery in treatment of cavernous malformations presenting with epilepsy. Neurosurg Rev 23:80-83, 2000

65. Smith MC: Multiple subpial transection in patients with extratemporal epilepsy. Epilepsia 39 (Suppl 4): S81-S89, 1998

66. Spencer DD, Spencer SS, Mattson RH, Williamson PD: Intracerebral masses in patients with intractable partial epilepsy. Neurology 34:432-436, 1984

67. Spencer SS: Corpus callosum section and other disconnection procedures for medically intractable epilepsy. Epilepsia 29 Suppl 2:S85-S99, 1988

68. Spencer SS, Spencer DD, Williamson PD, Sass K, Novelly RA, Mattson RH: Corpus callosotomy for epilepsy. I. Seizure effects. Neurology 38:19-24, 1988

69. Stefan H, Hammen T: Cavernous haemangiomas, epilepsy and treatment strategies. Acta Neurol Scand 110:393-397, 2004

70. Striano S, Nocerino C, Striano P, Boccella P, Meo R, Bilo L, et al: Venous angiomas and epilepsy. Neurol Sci 21:151-155, 2000

71. Tannier C, Pons M, Treil J: [Cerebral venous angiomas. 12 personal cases and review of the literature.] Rev Neurol (Paris) 147:356-363, 1991 (Fr)

72. Topper R, Jürgens E, Reul J, Thron A: Clinical significance of intracranial developmental venous anomalies. J Neurol Neurosurg Psychiatry 67:234-238, 1999

73. Van Roost D, Kristof R, Wolf HK, Keller E: Intracerebral capil- lary telangiectasia and venous malformation: a rare association. Surg Neurol 48: 175-183, 1997

74. Velasco F, Velasco M, Velasco AL, Jimenez F, Marquez I, Rise M: Electrical stimulation of the centromedian thalamic nucleus in control of seizures: long-term studies. Epilepsia 36:63-71, 1995

75. Velasco M, Velasco F, Velasco AL, Boleaga B, Jimenez F, Brito F, et al: Subacute electrical stimulation of the hippocampus blocks intractable temporal lobe seizures and paroxysmal EEG activities. Epilepsia 41:158-169, 2000

76. Weber JP, Silbergeld DL, Winn HR: Surgical resection of epileptogenic cortex associated with structural lesions. Neurosurg Clin N Am 4:327-336, 1993

77. Williamson A, Patrylo PR, Lee S, Spencer DD: Physiology of human cortical neurons adjacent to cavernous malformations and tumors. Epilepsia 44:1413-1419, 2003

78. Wilmore LJ, Triggs WJ, Gray JD: The role of iron-induced hippocampal peroxidation in acute epileptogenesis. Brain Res 382:422-426, 1986

79. Wilson DH, Reeves A, Gazzaniga M, Culver C: Cerebral commissurotomy for control of intractable seizures. Neurology 27: 708-715, 1977

80. Wurm G, Schnizer M, Fellner FA: Cerebral cavernous malformations associated with venous anomalies: surgical considerations. Neurosurgery 57 (1 Suppl):42-58, 2005

81. Yanaka K, Hyodo A, Nose T: Venous malformation serving as the draining vein of an adjoining arteriovenous malformation. Case report and review of the literature. Surg Neurol 56: 170-174, 2001

82. Yeh HS, Tew JM Jr, Gartner M: Seizure control after surgery on cerebral arteriovenous malformations. J Neurosurg 78:12-18, 1993

83. Zevgaridis D, van Velthoven V, Ebeling U, Reulen HJ: Seizure control following surgery in supratentorial cavernous malformations: a retrospective study in 77 patients. Acta Neurochir (Wien) 138:672-677, 1996

Manuscript received April 28, 2006.

Accepted in final form May 30, 2006.

Address reprint requests to: Issam Awad, M.D., Neurosurgery, Evanston Hospital Room 4215, 2650 Ridge Avenue, Evanston, IL 60201. email: iawad@enh.org. 